\title{
Article \\ A Biopsychosocial Perspective of User-Generated Innovation in Open Innovation Models: A Moderated-Mediation Analysis
}

\author{
Tahseen Arshi $^{1, *(D)}$, Venkoba Rao ${ }^{2}$ D, Kamal Qazi ${ }^{3}\left(\mathbb{D}\right.$, Vazeerjan Begum ${ }^{1}$, Mansoor ALSabahi ${ }^{4}$ \\ and Syed Ali Ahmed 5 (iD)
}

1 School of Business, American University of Ras Al Khaimah, Ras Al Khaimah 86416, United Arab Emirates; vazeerjan.begum@aurak.ac.ae

2 Faculty of Business Management, Majan University College, Muscat 112, Oman; venkoba.rao@majancollege.edu.om

3 Leeds Business School, Leeds Beckett University, Leeds LS1 3HE, UK; k.qazi@leedsbeckett.ac.uk

4 College of Business and Economics, United Arab Emirates University, Abu Dhabi 59911, United Arab Emirates; mansoor.alsabahi@hotmail.com

5 School of Engineering, SRM Institute of Science and Technology, Chennai 603203, India; syedali_ahmad17@srmuniv.edu.in

* Correspondence: tahseen.arshi@aurak.ac.ae

check for updates

Citation: Arshi, T.; Rao, V.; Qazi, K.; Begum, V.; ALSabahi, M.; Ahmed, S.A. A Biopsychosocial Perspective of User-Generated Innovation in Open Innovation Models: A

Moderated-Mediation Analysis. J. Open Innov. Technol. Mark. Complex. 2021, 7, 131. https://doi.org/ 10.3390/joitmc7020131

Received: 21 March 2021

Accepted: 2 May 2021

Published: 11 May 2021

Publisher's Note: MDPI stays neutral with regard to jurisdictional claims in published maps and institutional affiliations.

Copyright: (c) 2021 by the authors. Licensee MDPI, Basel, Switzerland. This article is an open access article distributed under the terms and conditions of the Creative Commons Attribution (CC BY) license (https:// creativecommons.org/licenses/by/ $4.0 /)$.

\begin{abstract}
User-generated innovation has contributed to the growth of the democratization of openinnovation models. One of the most common forms of user-generated innovation is evident on social media platforms. The purpose of this study is to investigate nonpecuniary motivations that drive innovation among user innovators on social media platforms. Furthermore, the study examines the underlying sociopsychological and biological dispositions that influence nonpecuniary motivation. The experimental and control group consisted of 204 user innovators on different social media platforms who filled out a self-reporting questionnaire in this exploratory research design. The study assessed endocrinal biomarkers through a proxy measure of 2D:4D ratio associated with behavioral, emotional, and social behavior. It developed a moderated-mediation model evaluating the indirect conditional relationships through a regression-based analysis with bootstrapped estimations. The findings support the moderated-mediation model, indicating that nonpecuniary motivation primarily explains user innovator behavior. Hedonic emotions, characterized by aesthetics, experiential enjoyment, and satisfaction-related feelings, mediate this relationship. A critical finding of the study is that endocrinal testosterone moderates this mediated relationship. This study is the first to apply a biopsychosocial lens to examine motivational drives influencing user-generated innovation using a moderated-mediation model. It contributes to understanding user innovators' tricky motivational purposes, emphasizing the role of human agency in advancing the open-innovation agenda.
\end{abstract}

Keywords: open innovation; user-generated innovation; pecuniary and nonpecuniary motivations; hedonic emotions; endocrinal testosterone; moderated mediation

\section{Introduction}

An avalanche of interest in open-innovation research has contributed to widening the scope of the field, its research, and its impact on industrial practice [1]. User-generated innovation (UGI), an essential constituent of open innovation, has received considerable attention recently. According to West et al. [2], user innovation shares similarities with open innovation, particularly in how the innovation is a distributed process. West et al. [2] defined user-driven innovation as user-generated innovativeness that creates value. Similarly, Von Hippel [3] explained that user innovators are "individuals who expect to benefit from using a product or a service, in contrast to manufacturers who expect to benefit from selling a product or a service." The user innovator creates and shares knowledge and activities outside the firm's domain, which forms an essential element of open innovation [4]. This permeation of organizational boundaries and democratized innovation makes 
user-generated innovation an attractive and intriguing research area. There are several other reasons for the growth of interest in user-generated innovation. User innovators are a critical source of external knowledge for the firm, and they invest time and money in generating innovation [5]. User innovators also provide new research opportunities due to their diverse ways of innovativeness, knowledge, and skills, which get assimilated into an organization's open-innovation agenda and create value. Existing research has not adequately explored the deeper psychosocial motivations of user innovators. Traditional models developed to explain user innovators' motivations do not specify the interplay of biopsychosocial mechanisms that trigger user innovators' desire to create and share innovation. The study aims to address these research gaps by developing a new model that includes multiple dimensions. Prominently, it incorporates biological influences, which can uncover some of the previously unexplained user innovators' motivational aspects.

Research suggests that social media sites and digital platforms are ideal for investigating user-generated innovation. The behaviors of users drive value on social media sites. There is growing interest in social media sites and their users' behavioral traits and characteristics [6]. According to Kemp [7], there are approximately 3.5 billion social media users with an overall penetration of $45 \%$ of the world's population. The social media and digital platforms operate through either a two-sided or multi-sided marketplace that allows assimilation of user-generated innovation [8,9]. Muzellec et al. [10] argued that two-sided online business models enable firms to monetize innovative value propositions. User innovators' motivation for knowledge flow can be varied, oscillating between pecuniary or nonpecuniary incentives. Although lead users in a two-sided marketplace enjoy certain financial benefits, most other user innovators cannot generate adequate revenues incentivized by their innovations. West and Gallagher [11] pointed to several psychological and social causes that drive user innovators. Researchers mainly assume that such users are generally motivated by nonpecuniary benefits [12]. The motivations behind nonpecuniary services are usually associated with utilitarian and hedonic considerations. Stock et al. [13] argued that nonpecuniary reasons are stronger with hedonic considerations but weaker with utilitarian motives. A dive into hedonic motivation takes one to deeper psychological factors, which interestingly are partly disposed to physiological conditions [14].

Considering that UGI, as it is mainly related to social media, is deeply embedded in the social fabric, sociopsychological traits can better explain the nonpecuniary drives in the cocreated innovation process. Since researchers emphasize human agency's role in problematic sociopsychological behaviors, there is a call to investigate the effect of deeper biological traits on actions and decisions [14]. Inadequacy of knowledge about many aspects of user traits that cocreate innovation has triggered this research call [15]. West and Bogers [16] recommended that new research on open innovation should explore individual users' motivations through mediated and moderated relationships. This study sets out to investigate deeper motives behind nonpecuniary knowledge flows and the role of emotions in user-generated innovation. Loewenstein [17] and Dolcos et al. [18] argued that emotions drive human motivation. This study advances this proposition that psychological and undisclosed intrinsic motives, as Franke et al. [19] and Stock et al. [13] pointed out, are triggered by deeper emotional states influenced by physiological drives. Such biological traits can uncover deeper social and psychological triggers that act as nonpecuniary motivation for unarticulated decisions [20]. These conceptual and empirical observations have driven this study to examine the psychological, social, and biological predispositions that cocreate innovation through a new model to uncover complex interactions. The study further analyses how physiological biomarkers trigger and moderate the user innovators' desire to create and share creation.

\section{Theoretical Background}

The role of individuals who contribute to open innovation has been studied both within and outside the firm [11,21-23]. The gap between open innovation and userinnovation research has recently narrowed, and the two communities are increasingly 
being merged [24]. Although there are commonalities between them, they differ in their motivations. While firms may be motivated by knowledge sourcing, IP and competitive benefits, and financial performance, user motivations may be covert and interact with many undisclosed factors [2].

User innovators include creative consumers [25], lead users, hackers [26], and online pirates [27] who significantly contribute to open innovation $[5,28]$. Studies on user innovators, particularly those who do not disclose their motivations to share and reveal their innovations without expecting financial outcomes, are growing [29,30]. Researchers are no longer restricting their studies to financial motivations alone but increasingly examine nonpecuniary incentives in innovation collaborations $[1,16,31-33]$. This revised nomological conceptualization has research implications for individual user innovators.

This study utilizes two approaches to explain nonpecuniary motivations for usergenerated innovation. Self-determination theory explains intrinsic behaviors targeted to drive individual growth [34]. Gagne and Deci [34] argued that positive feedback on individual performance boosts inherent motivation for development under weak extrinsic motivational conditions. Intrinsic motivation drives emotional feelings of autonomy and competence [35]. Another theory that can explain nonpecuniary incentives for user-generated innovation is James Lange's and subsequently Cannon-Bard's views of emotions [36,37]. Although differing on the temporal order of physiological influence, both theories recognized the importance of physiological triggers in emotional expression [20]. Furthermore, Olsson et al. [38] proposed an integrative model of raw emotions and found that endocrine hormones, particularly gonadal steroid testosterone, largely influenced sociocognitive and emotional regulation at various levels. Similarly, Nitschke et al. [39], Nadler et al. [40], and Buskens et al. [41] discovered the influence of testosterone-moderated social extraversion and the effect of homeostatic variance on emotional reactivity. This study posits nonpecuniary motivations as explained by self-determination theories (the desire of an individual to leverage intrinsic reasons for growth) as a central motivator. Furthermore, it argues that the theory of emotion (physiologically influenced emotions of joy, fun, excitement, and curiosity) explains nonpecuniary motivations. This study contributes to the open-innovation paradigm by demonstrating empirical evidence of social, emotional, and physiological influences on user-generated innovation.

\section{Review of Literature and Hypothesis Development}

\subsection{Asymmetric Nonpecuniary Motivations}

User-generated innovation is one of the intriguing open innovation trends [42]. Researchers are interested in user innovators' nonpecuniary motivations [30,43-45]. Users generate and share innovation without any expectation of financial compensation; hence their motivation is not well explained. Franke et al. [19] studied nonpecuniary motivations through psychological [19] or social [42], emotional or undisclosed intrinsic factors [13]. Verreynne et al. [46] explained that individual and firm motivations might vary because individual users have broader motivational agendas. Individual users who reveal their knowledge, particularly on social media platforms, do not always expect financial returns [47]. Jung et al. [15] attributed nonpecuniary benefits among user innovators to hedonic emotions related to enjoyment, satisfaction, social extraversion, social empathy, and altruism. Chitturi et al. [48] posited that hedonic feelings result from an interplay of cognitive and social factors. Botti and McGill [49] argued that "Preferences for hedonic tasks and goods are emotionally driven, whereas those for utilitarian tasks and goods are cognitively driven." West [21] concluded that the conflicting motivations between the firm and individual user and appropriation logic need a more in-depth investigation of social and emotional factors.

\subsection{Hedonic Emotions}

Another dimension closely associated with the nonpecuniary motivations of user innovators' is their emotions. Vittersø [50] and Disabato et al. [51] explained that individuals 
seek to maintain biopsychosocial well-being through diverse emotional functions. Hedonic emotion is one such emotional function to maintain homeostatic balance. De Dreu et al. [52] found links between hedonic emotions and creativity and innovativeness. Through the hedonic feeling of pleasure and life satisfaction, user innovators are motivated to share innovation without financial gains. Berthon et al. [53] argued that hedonic emotions enable individuals to develop social and emotional capital. Researchers have determined that utilitarian and hedonic motivations drive user behavior on online and social media platforms [54,55]. Stock et al. [13] argued that practical motives for the innovativeness of user-generated innovation are elicited by a desire to be rewarded with the value created through innovation. They argued that users could find better utility in established products and services, and hence the practical drives are weaker. They discovered that hedonic emotions primarily drive UGI on social media platforms. Hedonic motivations are more intangible and intrinsically governed by the emotional desire for enjoyment, learning, and social extraversion [56,57].

Similarly, Füller et al. [58] and Nambisan and Baron [59] associated hedonic emotions with fun, curiosity, and learning. According to Chagas et al. [54], the role of hedonic emotions in collaborative innovation practices evidences their importance in understanding the unbalanced appropriation logic in open-innovation models. Berthon et al. [53] explained that hedonic benefits can compensate for weaker appropriation as user innovators build emotional capital through their innovativeness. The emotional property develops due to the emotional investment in the creation and the attachment to the outcomes themselves. As a result, the creator feels ownership of the invention [53]. Hedonic emotions are more robust because user innovators enjoy the process of creation and, to some extent, the value of the utility created [34].

\subsection{Biosocial Influences: Testosterone}

Nicolaou et al. [14] argued that the interaction between human biology and the environment could account for certain human behaviors. They further posited that biological factors' inclusion in traditional models could give more insights into unexplained behaviors. Such integrated models can maximize the variance explained and make social, psychological, and economic considerations more relevant. Nicolaou et al. [14] cautioned that biological influences do not cause behaviors but rather influence how actions are expressed based on the individual and environmental contexts.

One stream of biological research, which has received considerable attention in exploring human behaviors, is physiology and hormonal influences. The testosterone hormone is an androgen produced both in men and women, affecting cognitive structures and psychological processes [60]. Researchers found the testosterone hormone to be influencing entrepreneurial behavior [61-64]. White et al. [60] posited that the testosterone hormone could either moderate or mediate human behavior. They further highlighted that testosterone generally acts in tandem with other psychological and social markers to moderate human entrepreneurial behavior. Exploring the drives for hedonic emotions, Bettiga et al. [65] found physiological and neural influences on emotional behavior. Utilizing neuroimaging techniques, Yue et al. [66], Chester and DeWall [67], and Geurts [68] discovered that neural excitement, triggered by homeostatic mechanisms, regulates emotions. Buchholz et al. [69], through a biosocial study, associated hormonal influences with emotional regulation and sociability.

The research on the relationship between testosterone's influences on hedonic emotions and user motives for innovation creation is limited [70]. It provides the scope for exploring testosterone's effect on user innovator's behavior as the existing research substantially indicates such influence. Eisenegger et al. [71] and Newman et al. [72] specifically found supporting evidence of prenatal testosterone's effect on the desire for socialization, social status, and building social networks. Similarly, Grant and France [73] and Dabs et al. [74] discovered testosterone's influence on behaviors such as the need for achievement, independence, social status, and expressive styles. The study argues that it can 
be suitable to research the motives for conflicting appropriation logic between the firm and the individual user innovators. Testosterone's role in the context of social network sites also warrants investigation because it influences social behaviors. Booth et al. [75] argued that "the role of testosterone in how humans express social behavior has often been linked to behaviors concerning maintaining social status, such as dominance, aggression, competition, and prosocial behavior, as well as various affiliative behaviors ... ." (p. 170). Researchers have found testosterone's influence on creativity and innovative behavior. Hassler [76] found the effect of testosterone on originality, artistic, and musical talent. Researchers also found the impact of testosterone on variety-seeking behavior, desire for growth, social extraversion, and risk-taking [71,72,76-79].

Overall, the literature provides substantial pieces of evidence of biopsychosocial influences on user-generated innovation. However, it falls short of providing an integrated view of their direct, mediated, and moderated effects. It leads to the development of the following hypotheses.

Hypothesis 1. There is a significant positive relationship between nonpecuniary motivation and user-generated innovation.

Hypothesis 2. Hedonic emotion mediates the relationship between nonpecuniary motivation and user-generated innovation.

Hypothesis 3. Testosterone positively moderates the relationship between nonpecuniary motivation and hedonic emotions.

Hypothesis 4. Testosterone positively moderates the relationship between hedonic emotions and user-generated innovation.

\subsection{Study Framework}

The study considers several variables that can be attributed to user-generated innovation. It posits nonpecuniary motivation (NPM) as an independent variable, user-generated innovation (UGI) as the dependent variable, and hedonic emotion (HE) as the mediated variable. Testosterone level (TL) (an endocrinal biomarker) moderates the relationship between NPM and HE and subsequently between HE and UGI. Nonpecuniary motivation is defined as the desire to reveal unique knowledge and skills to others without expecting monetary benefits $[1,15]$. Hedonic emotion is defined as intrinsic, aesthetic, experiential, and enjoyment and satisfaction-related feelings $[48,58,59,80]$.

The research framework (Figure 1) is a moderated-mediation model based on Muller et al.'s [81] suggestion. It illustrates that nonpecuniary motivation (NPM) has a significantly positive effect on user-generated innovation. Hedonic emotions mediate this relationship as feelings of enjoyment and satisfaction support motivational drives. Testosterone levels influence the strength of the desire for hedonic feelings (mediated path a) and subsequently the desire to create and share innovation (mediated path $b$ ). Therefore, prenatal testosterone's moderation effect is on the mediated relationship rather than a direct connection between NPM and UGI (total effect path c). The users' age, domain skills, and investments in innovation projects are controlled because they could interfere with generalization. 


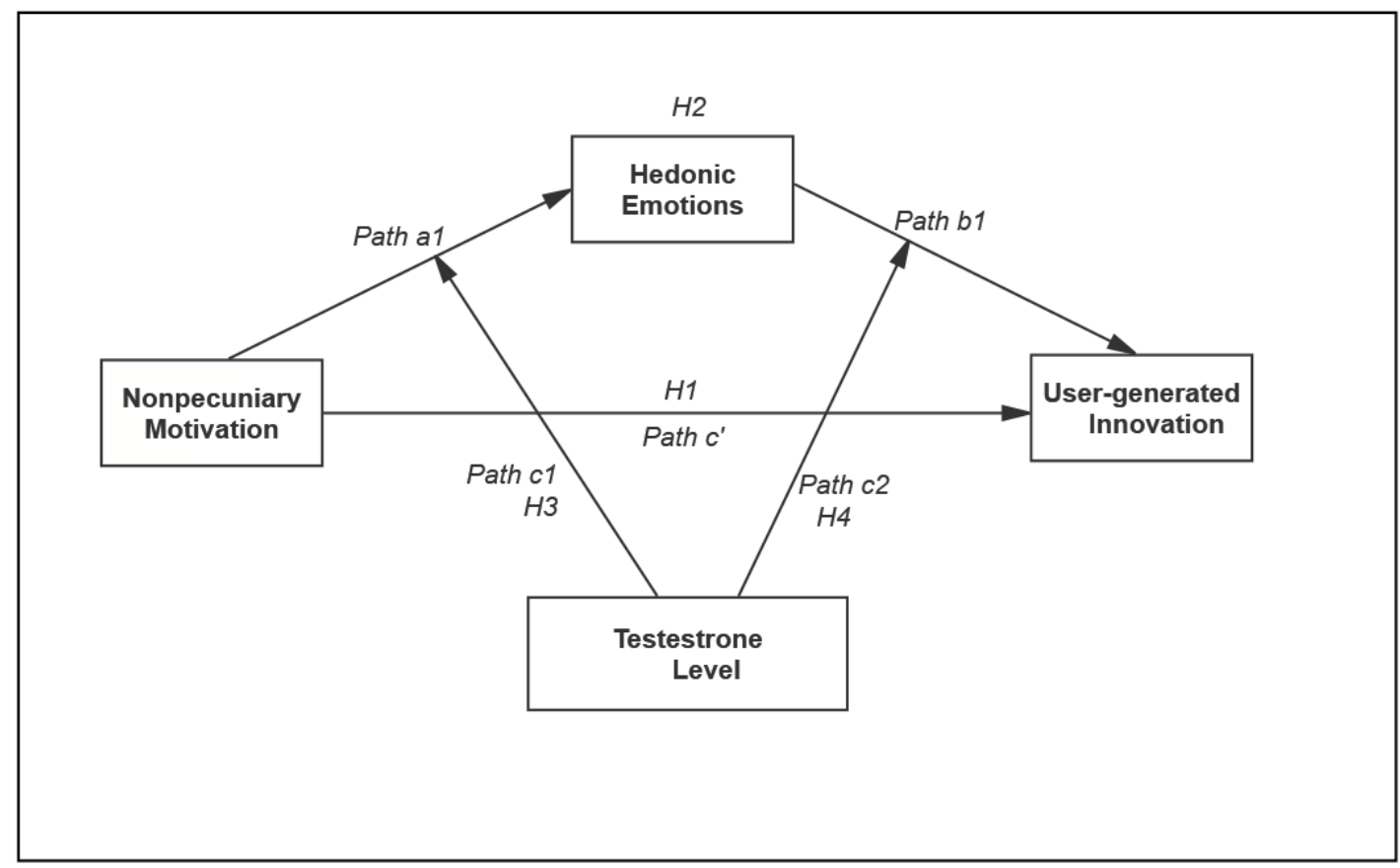

Figure 1. Research Framework: Moderated-Mediation Model- Panel c'- H1, Panel a1b1-H2, Panel c1a1- H3, Panel c2b1-H4.

\section{Materials and Methods}

The study adopts a quantitative approach due to the measurement requirements of relationships and numerical data. Furthermore, quantitative research is well suited to testing the moderated-mediation model [82]. The indirect conditional analysis was examined through regression-based analysis using IBM Statistical Package for the Social Sciences (SPSS). The research utilized SPSS macro (version 20) with bootstrapping estimations as proposed by Preacher et al. [82], and illustrated by Hayes [83]. The study also utilized Mplus (version 8.0) for data analysis. The following regression equation was constructed for the moderated-mediation model, where NPM = independent variable, UGI = outcome variable, $\mathrm{HE}=$ mediator variable, and $\mathrm{TL}=$ moderator variable.

$$
\mathrm{UGI}=\mathrm{HE} 40+\mathrm{HE} 41 \mathrm{NPM}+\mathrm{HE} 42 \mathrm{TL}+\mathrm{HE} 43 \mathrm{NPMTL}+\varepsilon 4
$$

\subsection{Sample}

The study floated an advertisement on Facebook inviting individual user innovators to participate in the study. The objective of the research was a social experiment. It attracted the interest of almost 275 users of different social media platforms, namely Facebook, Twitter, Instagram, LinkedIn, WhatsApp, YouTube, and Pinterest. The inclusion and exclusion criteria were made clear in the advertisement. The study used the following inclusion and exclusion criteria. Participants had to be over 18 years of age, and should have demonstrated at least one innovation in social media platforms. The study excluded those participants who could not provide satisfactory evidence of innovation or were not active on social media for more than three months. The National Accreditation Board for Hospital and Healthcare in India and Dubai Scientific Research Ethics Committee, affirming the principles of the declaration of the Helsinki Ethics Committee, approved the study. The cross-sectional data were collected through a structured online questionnaire, the link to which was provided on Facebook. A total of 204 participants met the inclusion criteria, and the rest of the responses were excluded from the analysis.

\subsection{Measures}

Hedonic emotions were measured through the hedonic scale (12 items, $\alpha=0.92$, AVE ranged from 0.47 to 0.50 ) developed by Eric et al. [84], who considered all positive 
emotions on the scale. The nonpecuniary motivations were measured utilizing the studies of West [21], Eisenegger et al., [71], and Gleason [85]. It contained 4 measures of desire for social interaction, social contribution, social status, and social recognition [19]. The user innovation included measures adopted from the studies of Ma et al. [86] and Stock et al. [13]. It is comprised of 5 measures on creative solutions, novelty, artwork, knowledge, and skills. The study measured testosterone levels through a proxy measure of a $2 \mathrm{~d}: 4 \mathrm{~d}$ ratio associated with behavioral disposition, including social and emotional behavior [87]. The digit (2D:4D) ratio is derived by dividing the length of index (2D) and ring (4D) fingers [88]. Berenbaum et al. [89] and Hönekopp and Watson [90] confirmed through several other studies that the 2nd and 4th fingers are proxy biomarkers for prenatal testosterone exposure.

\subsection{Analytical Procedure}

The respondents filled in the self-reporting online questionnaire comprised of 19 structured Likert-type questions on a scale of 1 (strongly disagree) to 5 (strongly agree). The respondents were also asked to scan the length of their index and ring fingers using commonly available document scanners. The study quantified the ratios through the GNU Image Manipulation Program (GIMP 2.8; https: / / www.gimp.org) (accessed on 12 September 2020). Two independent raters measured the index's scanned images (2D) and ring (4D) fingers. The inter-rater reliability was established through the two-way inter-rater correlation coefficient (full agreement). The values of the 2D:4D were calculated through the mean values of the left and right hand (M2D:4D). The right-hand values were coded as R2D:4D and the left-hand as L2D:4D. The difference between R2D:4D and L2D:4D was calculated as 2D:4D1-r. Siegmann et al. [91], citing Manning et al. [92], argued that low 2D:4D1-r values were associated with high prenatal testosterone exposures. The sample was divided into an experimental $(n=103)$ and a control group $(n=101)$. The student's $t$-test was used to compare the M2D:4D, R2D:4D, L2D:4D, and 2D:4Dr-1 for the experimental and control groups. The study used the $\chi 2$ test to analyze the differences in the frequency of nominal variables. The 2D:4D measures and their continuous relationship with HE and UGI scores in both experimental and control groups were measured through Pearson correlations. Mean values and standard deviation scores are presented with statistical significance fixed at $p<0.05$ (2-sided).

The study analyzed the mediation effects by introducing the mediator variable and checking the total and the direct impact between NPM and UGI. Subgroup analysis was additionally performed to reduce the bias of (and probably low statistical power of) estimation parameters usually evident in mediation paths. Subgrouping analysis enabled analysis of moderated effects on both paths (path a and path $b$ ). The moderation and mediation methods were combined as Preacher et al. [93] and Edward et al. [94] suggested to test the moderated-mediation model's indirect and direct effects. The interaction plots were analyzed through a simple slope analysis, as Wang et al. [95] suggested. The study utilized bootstrapped standard errors using the maximum likelihood method (ML) to analyze the simple path effects. The total and conditional indirect effects were assessed through a bootstrapping procedure with 2000 bootstrapped samples.

\section{Results and Analysis of Data}

\subsection{Descriptive Statistical Analyses}

In all, 38\% of the participants reported user innovation through Facebook. Another $36 \%$ of the participants reported contributions through YouTube, with 16\% through Instagram, $4 \%$ through WhatsApp, and $2 \%$ each through Twitter, LinkedIn, and Pinterest. The participant age ranged from 18 to 33 years. Among the participants, $68 \%$ were men, while $32 \%$ were women. The participants were from 8 different countries, including Australia, the United Kingdom, the United Arab Emirates, Oman, India, Italy, Germany, and the United States. The range of user investments in developing innovation through social media channels ranged from USD 300 to USD 1200, while the number of contributions from each participant ranged from 2 to 7 . The data were firstly checked for internal consistency 
and reliability. Table 1 shows that the Cronbach's alpha values for all the three continuous scale items were $>0.070$, thereby establishing satisfactory reliability. The Pearson correlations matrix results shows positive correlations between NPM, HE, UGI, and TL composite measures and the square root of the average variance extracted (sqrt-AVE) for each construct against its correlation square compared to other constructs. The sqrt-AVE was greater than the inter-construct correlation square. Accordingly, discriminant validity was established as the sqrt-AVE value was greater than AVE in comparable latent constructs and higher than the correlation square of that variable with other constructs $(>0.5)$.

The study employed exploratory factor analysis (EFA) to analyze the shared variance of measured variables attributable to the latent factor [96]; EFA also enabled the research to understand the intricate interrelationships among groups of measures that are part of a unified construct [97]. The study chose principal component analysis with an oblique method, using promax rotation. It used goodness of fit measures to determine the number of factors and ultimately choose a model that explained the data better than simple or complex models. The result of the comparative model fit shown in Table 2 shows that the three-factor model comprising nonpecuniary motivation, hedonic emotions, and usergenerated innovation is the best model fit $(\mathrm{CFI}>0.9$ and RMSEA $<0.05)$. The pattern matrix for the three-factor model showed that the items loaded on to their factors without cross-loadings. Table 3 shows the AVE for all scale item, factor scores, and standard alpha.

The homogeneity of variance test showed that the sample did not display any heteroscedasticity (Levene's Statistic $>0.05$ ). Since the assumption of homogeneity of variance was tenable, the ANOVA scores were analyzed, which showed a significance, $>0.05$, confirming no statistically significant difference between groups. The data were subjected to tests of validity using structural equation modeling. The measurement model (MM) confirmed the three constructs' factorial structures because the items loaded significantly to the assigned factors.

All factor loadings were $>0.60$, indicating convergent validity. The measurement model (MM) showed a good data fit $(\chi 2(217)=319.03, p<0.01$; GFI $=9.81, \mathrm{CFI}=0.972$; TLI $=0.967 ;$ RMSEA $=0.021)$. Further, confirmatory factor analysis $(\mathrm{CFA})$ was performed to confirm whether the factors reflect the items by feeding the exact number of items identified through EFA. The results in Table 4 show that the group of items loaded well $(>0.60)$ and the total variance explained also showed the validity of items $(>0.60)$.

Table 1. Mean, standard deviation, correlations matrix and square root of the average variance extracted (in parenthesis).

\begin{tabular}{ccccccc}
\hline Variable & Mean & Std Dev & NPM & HE & UGI & TL \\
\hline NPM & 4.016 & 0.711 & $(0.798)$ & & & \\
\hline HE & 4.094 & 0.684 & $0.297^{* *}$ & $(0.823)$ & & \\
\hline UGI & 4.011 & 0.604 & $0.328^{* *}$ & $0.183^{* *}$ & $(0.759)$ & \\
\hline TL & 3.927 & 0.726 & $0.148^{*}$ & $0.132^{*}$ & $0.247^{* *}$ & - \\
\hline$n=204{ }^{*} p<0.05 ;{ }^{* *} p<0.01 ;^{* * *} p<0.001$. & & & &
\end{tabular}

Table 2. Model fit comparisons using fit-index measures.

\begin{tabular}{ccccc}
\hline Model & $\mathbf{X 2}(\mathbf{d f}), \boldsymbol{p}$ Value & CFI & RMSEA & SRMR \\
\hline One Factor & $4.46 .827(75), p<0.001$ & 0.958 & 0.102 & 0.052 \\
\hline Two Factor & $2.91 .623(52), p<0.001$ & 0.974 & 0.095 & 0.036 \\
\hline Three Factor & $1.48 .236(39), p<0.001$ & 0.989 & 0.049 & 0.023 \\
\hline
\end{tabular}


Table 3. Factor loadings, alpha scores, and average variance extracted (AVE) scores.

\begin{tabular}{lcc}
\hline \multicolumn{1}{c}{ Variables and Their Scale Items } & Factor Score & Standard Alpha \\
\hline Nonpecuniary motivations & 0.79 & $0.81(0.78)$ \\
1. I have a strong desire for social interaction. & 0.75 & 0.71 \\
2. I have a strong passion for social contribution. & 0.68 \\
3. I have a strong passion for social status. & \\
4. I have a strong passion for social recognition. & 0.81 \\
\hline Hedonic Emotions & 0.77 \\
1. I have a feeling of excitement when I contribute. & 0.78 \\
2. I have a feeling of delightfulness when I contribute. & 0.69 \\
3. I feel a sensual pleasure when I contribute. & 0.68 \\
4. I have a feeling of fun when I contribute. & 0.71 \\
5. I feel thrilled when I contribute. & 0.73 \\
6. I feel happy when I contribute. & 0.75 \\
7. Playfulness associated with creative work motivates me. & 0.62 \\
8. I enjoy doing creative work and contributing. & $0.84(0.79)$ \\
9. I feel cheerful whenever I engage in creative work. & 0.77 \\
10. I feel amused at the creative work of others, and it inspires me. & 0.71 \\
11. Funny creations keep my interests high. & 0.6 \\
12. Sensuous creations motivate me. & \\
\hline User-generated innovation & 0.68 \\
1. I have contributed to social media through creative solutions. & 0.7 \\
2. I can classify my creative solutions as novel. & 0.78 \\
3. I have created artistic work on social media. & 0.66 \\
4. Through my knowledge, I have created novel ideas. & 0.72 \\
5. Through my skills, I have created new opportunities. & \\
\hline
\end{tabular}

$n=204$, Kaiser-Meyer-Olkin (KMO scores in parentheses).

Table 4. Confirmatory factor analysis of all study variables.

\begin{tabular}{ccccc}
\hline Dimensions & Factor Loadings & $\begin{array}{c}\text { Total Variance } \\
\text { Explained }\end{array}$ & $\begin{array}{c}\text { Kaiser-Meyer-Okine } \\
\text { Measure }\end{array}$ & Bartlett's Test \\
\hline Nonpecuniary Motivation (5 Items) & $>0.60$ & 77.649 & 0.726 & 575.022 \\
\hline Hedonic Emotions (12 items) & $>0.60$ & 78.147 & 0.823 & 497.081 \\
\hline User-Generated Innovation (5 items) & $>0.60$ & 62.041 & 0.730 & 529.948 \\
\hline
\end{tabular}

The mean values of the independent, mediated and dependent, moderator and control variables were calculated. Table 5 shows no significant differences in the sociodemographic characteristics between the experimental and control groups. The $t$ scores showed no significant difference between mean distributions between the groups. The mean values of NPM, HE, and UGI were higher in the experimental group than in the control group, indicating the more substantial influence of NPM and hedonic emotions. The study found that the M2D:4D, R2D:4D, and L2D:4D and 2D:4Dr-1 in the experimental group were also higher than in the control group. The NPM, HE, and UGI scores correlated (Pearson correlation) positively and significantly with M2D:4D and R2D:4D in the experimental group ( $p<0.0001)$. There was also a significant association of NPM, HE, and UGI among the control group, but at lower significance levels $(p<0.05)$. 
Table 5. Digit ratio (2D:4D) group comparison: experimental and control groups.

\begin{tabular}{|c|c|c|c|c|c|c|c|c|c|}
\hline Variables & Experimental Group & & & & Control Group & & & & \\
\hline & $n$ & Mean & SD & $p$ & $n$ & Mean & SD & $t, x^{2}$ & $p$ \\
\hline Users' age & 103 & 24.5 & 12 & 0.107 & 101 & 23.1 & 13.2 & 0.9 & 0.231 \\
\hline Investment (USD) & 103 & 700 & 5 & 0.201 & 101 & 850 & 4.9 & 0.7 & 0.412 \\
\hline Contributions & 103 & 3.7 & 4.6 & 0.151 & 101 & 2.9 & 3.6 & 1.2 & 0.160 \\
\hline NPM (IV) & 103 & 4.1 & 0.2 & $<0.001$ & 101 & 183 & 3.9 & 1.1 & $<0.001$ \\
\hline HE (MV) & 103 & 4.3 & 0.3 & $<0.001$ & 101 & 1.1 & 4.1 & 0.8 & $<0.001$ \\
\hline UGI (DV) & 103 & 3.9 & 0.4 & $<0.001$ & 101 & 1.1 & 3.7 & 1.6 & $<0.001$ \\
\hline M2D:4D & 103 & 0.966 & 0.027 & $<0.001$ & 101 & 0.964 & 0.029 & -1.4 & $<0.05$ \\
\hline R2D:4D & 103 & 0.963 & 0.03 & $<0.001$ & 101 & 0.961 & 0.028 & 0.3 & $<0.05$ \\
\hline L2D:4D & 103 & 0.969 & 0.029 & $<0.001$ & 101 & 0.963 & 0.03 & 0.3 & $<0.05$ \\
\hline 2D:4Dr-1 & 103 & -0.007 & 0.021 & $<0.001$ & 101 & -0.03 & 0.021 & 0.4 & $<0.05$ \\
\hline
\end{tabular}

NPM hedonic scale (absolute range 1-5; higher scores indicate stronger nonpecuniary motivations), HE measures (complete range 1-5; higher scores indicate stronger hedonic emotions), MSD mean = R2D:4D and L2D:4D, the 2D:4Dr-l difference between R2D:4D and L2D:4D, $\mathrm{d}=$ Cohen's d. $p<0.05$.

\subsection{Mediation Analysis}

The study conducted a mediation analysis for the complete research model $(n=204)$. Table 6 shows the direct effect of NPM on UGI-the estimated value of $0.214(p>0.05)$, indicating that UPM has no direct and positive impact on user innovation. However, once the mediator variable (HE) was introduced into the model, the estimated values between NPM and HE (path a1) were 0.782 , and between HE and UGI (path b1) were 0.740 $(p<0.0001)$ (Table 7). The data indicated complete mediation because the relationship between NPM and UI (path c') was not significant before the mediator entered the model.

Table 6. Path estimates before and after testing for mediation.

\begin{tabular}{|c|c|c|c|c|c|c|c|}
\hline & & & Beta Estimate & SE. & CR. & $p$-Value & Result \\
\hline NPM & $<-$ & UGI & 0.214 & 0.304 & 7.131 & 1.55 & Significant \\
\hline
\end{tabular}

Table 7. Path estimates after inclusion of mediator variable.

\begin{tabular}{cccccccc}
\hline & & & Beta Estimate & SE. & CR. & $p$-Value & Result \\
\hline UGI & $<-$ & NPM & 0.140 & 0.110 & 5.191 & 0.331 & Not Significant \\
\hline HE & $<-$ & NPM & $0.782^{* * *}$ & 0.187 & 4.012 & 0.000 & Significant \\
\hline UGI & $<-$ & HE & $0.740^{* * *}$ & 0.198 & 2.011 & 0.000 & Significant \\
\hline Note: $n=204^{* *} p<0.05^{* *} p<0.01 ;^{* * *} p<0.001$. & & & &
\end{tabular}

After the mediator variable (HE) enters the model:

Subsequently, the study conducted a separate conditional effect analysis for experimental and control groups. A review of indirect effects from 2000 bootstrapped samples showed that both paths in the research model, namely a1b1 and c, were statistically significant ( $95 \%$ confidence intervals) (Table 8 ). The simple effects differences were calculated by subtracting the control group's results from the experimental group's effects. Bias-corrected confidence intervals were calculated from bootstrapped estimates.

The control group's effects were subtracted from the experimental group's effects to compute the differences in simple effects. Differences tests for the indirect impact were based on bias-corrected confidence intervals derived from bootstrap estimates. Among the control group, there was some evidence of direct effects, but in the control group, the relationships were not significant $(p>0.05)$ (path $\left.c^{\prime}\right)$. Based on the data, an indirect conditional relationship 
exists between NPM and UGI because HE strongly mediates NPM and UGI. Based on the findings, the study accepts $\mathrm{H} 1$ and $\mathrm{H} 2$, which postulated a conditional relationship.

Table 8. Analysis of simple effects (group level using maximum likelihood estimation).

\begin{tabular}{ccccc}
\hline Moderator Variable & \multicolumn{4}{c}{ Effect } \\
\hline Experimental Group & $\mathrm{a} 1$ & $\mathrm{~b} 1$ & $\mathrm{c}^{\prime}$ & $\mathrm{a} 1 \mathrm{~b} 1$ \\
\hline Control Group & $0.697^{* * *}$ & $0.649^{* * *}$ & $0.215^{*}$ & -0.06 \\
\hline Difference & $0.573^{* *}$ & $0.275^{* *}$ & 0.041 & 0.042 \\
\hline${ }^{*} p<0.05 ;{ }^{* *} p<0.01{ }^{* * *} p<0.001$. & -0.379 & -0.104 & $1.237^{*}$ & -0.045 \\
\hline
\end{tabular}

\subsection{Moderation Analysis}

Before regressing the variables and checking for moderation effect, multicollinearity was analyzed as suggested by Tabachnik and Fidell [98]. A variance inflationary factor (VIF) of $<0.2$ indicated no data inflation due to multicollinearity. To ensure improvement of interpretation of regression equations, mean centering was performed. Firstly predictors were mean-centered, subtracting the mean from all individual scores. Secondly, the interaction predictor was computed with predictors as the output of the mean-centered predictors. Finally, a regression test was conducted with mean-centered predictors and the interaction predictor. Furthermore, tests for moderated-mediation were conducted (Table 9 and Figure 2). The results show that the moderating effect of testosterone level (paths c1) and interaction effects of TL and NPM (path c2) on user innovation were statistically significant $(p<0.05)$. The indirect effects (a1 and b1) were also statistically significant. The coefficient of the indirect effect of NPM via hedonic emotions (a1b1) was 0.771, accounting for $68 \%$ of the indirect effects. The TL's direct influence on NPM and UGI was 0.379 and accounted for $32 \%$ of the indirect effects. The $95 \%$ percentile for confidence intervals for bootstrapped distributions was expressed through the scores of the upper and lower $2.5 \%$ of each distribution. The differences between the percentile and bias-corrected methods were noted with a slight advantage for the percentile method, mostly when bias-corrected method scores were relaxed. Based on the data evidence, the study accepts $\mathrm{H} 3$ because the moderated-mediation relationship was supported.

Table 9. Bootstrap mediation and moderated-mediation effect.

\begin{tabular}{|c|c|c|c|c|c|c|c|}
\hline & Estimate & & & Bootstrap 2000 95\% & & & \\
\hline & & & & Bias-corrected & & Percentile & \\
\hline Mediated Model & & SE. & Est./S.E & Lower & Upper & Lower & Upper \\
\hline \multicolumn{8}{|l|}{ Indirect Effect } \\
\hline NPM-HE-UGI & $0.771^{* * *}$ & 0.036 & 2.578 & 0.120 & 0.027 & 0.128 & 0.024 \\
\hline Total Indirect Effect & $0.483^{* *}$ & 0.053 & 4.818 & 0.312 & 0.135 & 0.297 & 0.125 \\
\hline \multicolumn{8}{|c|}{ Moderated-Mediation Model } \\
\hline NPM-TL-UGI & $0.379 * * *$ & 0.027 & 1.847 & 0.114 & 0.008 & 0.095 & 0.003 \\
\hline \multicolumn{8}{|l|}{ Total Indirect Effect } \\
\hline Total Indirect Effect & $0.267^{* * *}$ & 0.045 & 3.785 & 0.165 & -0.091 & 0.259 & 0.087 \\
\hline
\end{tabular}

CI—confidence interval, SE—standard error, NPM—nonpecuniary motivation, TL-testosterone level, UGI—user-generated innovation. ${ }^{*} p<0.05 ;{ }^{* *} p<0.01 ; * * * 0.001$. 


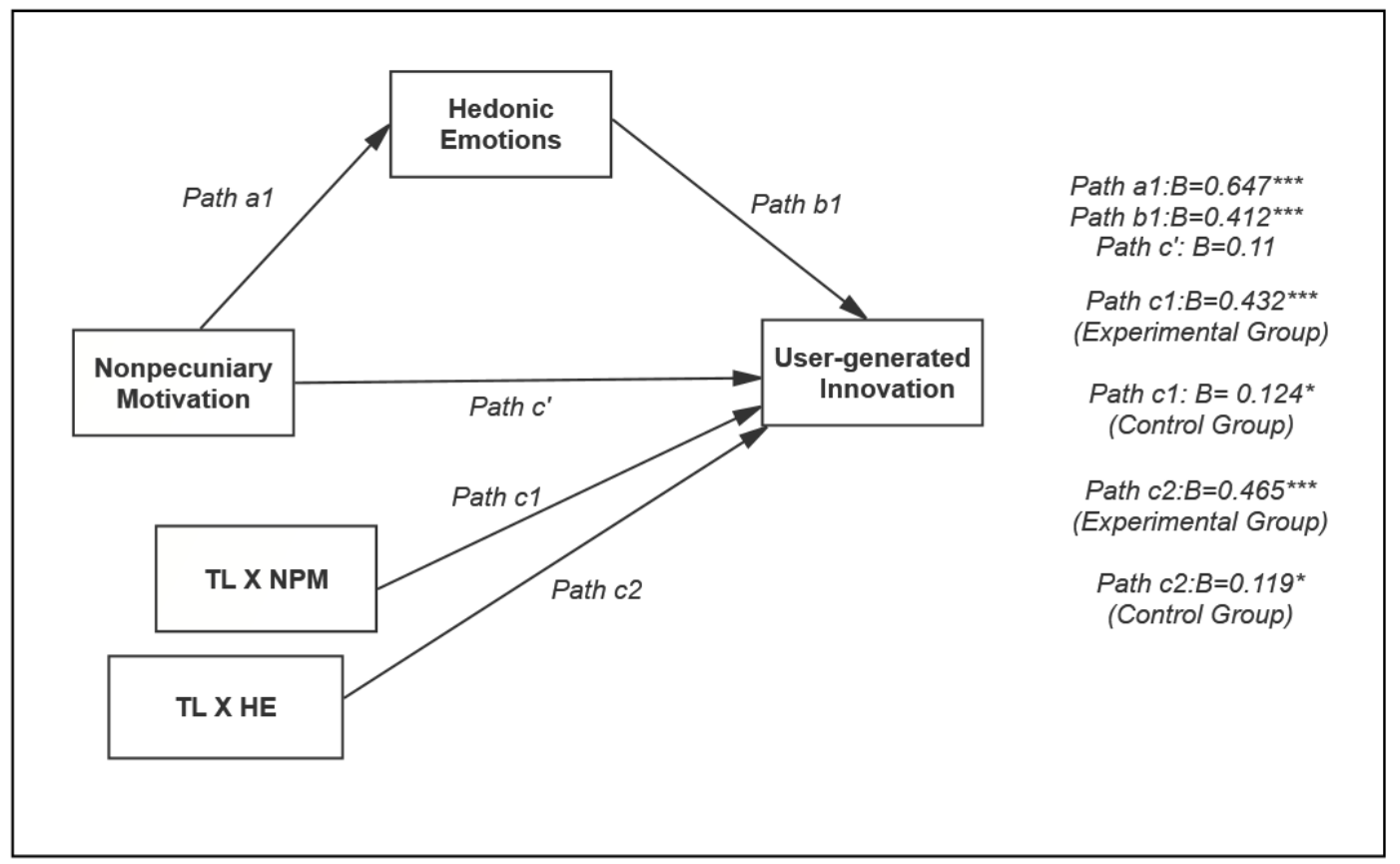

Figure 2. Statistical Moderated-Mediation Model ${ }^{*} p<0.05 ;{ }^{* *} p<0.01^{* * *} p<0.001$ - the effect of Nonpecuniary Motivation (NPM) on User-generated Innovation (UGI) is mediated through Hedonic Emotions (HE), and moderated by Testosterone (TL).

\subsection{Moderated-Mediation Analysis}

Considering that ordinary least square (OLS) regression showed the best fit for the moderated-mediation model, the study tested several model-fit parameters such as the ANOVA F-test and $\mathrm{R}^{2}$ to measure model fit. The OLS regression helped minimize the sum of the squared residuals and analyze the variation in an outcome explained with a particular model. The study results showed that $R^{2}$ for the moderated-mediation model increased (0.78) compared to the baseline two-factor direct causal relationship model (0.59). It indicated that the moderated-mediation model explained most of the variability of the response data around its mean. Given the sensitivity of $R^{2}$ to the number of variables, the study conducted an ANOVA F-test to compare the residuals from the moderatedmediation model to the baseline two-factor model. The results indicated a difference in the model fit as a significant value of the sum of squared residuals, and a large F-statistic for baseline two-factor model was evident. Further, there was a substantial reduction in the sum of squared residuals in the moderated-mediation model, indicating a better model fit.

The results of the moderated-mediation statistical model (Figure 2) fully support hypotheses 2,3 , and 4 . The beta coefficient (path $\mathrm{c}^{\prime}$-direct relationship) is not supported $(\mathrm{B}=0.11, p>0.05$ ). The results support the mediated relationship (paths a1b1, $\mathrm{B}=0.647$ and $0.412, p<0.001$ ). The interaction between the independent variable and moderator variable was statistically significant, supporting the moderating effect (Figure 2 below- c2experimental group $0.465^{* * *}$ control group $0.119^{* *}$ ).

The moderated-mediation relationship between NPM and HE and HE and UGI via $\mathrm{TL}$ is well supported (path $\mathrm{c} 1 \mathrm{~B}=0.432$ ) and (path $\mathrm{c} 2, \mathrm{~B}=0.465, p<0.001$ ). Finally, beta coefficient values on paths $\mathrm{c} 1$ and $\mathrm{c} 2$ are higher for the experimental group than for the control group.

\section{Discussion}

Limited empirical evidence exists on the nonpecuniary motivations of user innovators on open innovation platforms. A significant obstacle that obscured the understanding of user innovators' motivation is the lack of an integrated model incorporating psychological, social, and biological influences on user-innovator behavior. Therefore, the study attempted to fill the gap by investigating deeper motivations and the multiple and synergistic effects 
of biopsychosocial factors. It is one of the first studies that specifically examined the role of testosterone's hedonic emotions and biological influences in driving user-generated innovation. The study employed self-determination and positive social aggression theories to explain the emotional and social undercurrents associated with nonpecuniary motivation and hedonic emotions $[34,36,37]$. It posited that on social media platforms, user innovators contributed to open innovation due to an inherent desire for emotional and social rewards influenced by physiological conditions (Booth et al. [75]). A significant contribution of the study is the conceptualization and testing of a moderated-mediation model, which explains the conditional nonpecuniary hedonic motives. The varied motivations act as necessary contingencies for open-innovation effectiveness. The findings indicated that hedonic emotions mostly explained the predictive effect of nonpecuniary stimulation on usergenerated innovation, and testosterone levels buffered it. Thus, the study established a new moderated-mediation model to describe complex motivations associated with usergenerated innovation.

\subsection{Relationship between Nonpecuniary Motivation and User Innovation}

The first hypothesis focused on one of the most neglected aspects-the relationship between nonpecuniary motivation and user-generated innovation. Results suggest that nonpecuniary motives drive an individual's innovation goals. This indicates that user innovators are propelled by various nonpecuniary reasons to participate in open innovations [15]. On social media platforms, user innovators derive many nonpecuniary returns for their innovations, which might include intrinsic rewards such as fun, enjoyment of intellectual challenges, prosocial rewards like identification with the project or the community, a sense of belonging, and good citizenship. Hence, the study concurs with Klaß [99], Brinks [100], Arshi [101], and Lakhani et al. [26] that nonpecuniary intrinsic rewards like learning, reputation gains, and acknowledgment/symbolic rewards foster diffusion of ideas. The findings resonate with those of Macdonald [102], who stated that revealing knowledge without the expectation of monetary gain is inevitable as protecting ability becomes impractical in a connected environment. A nonpecuniary setting becomes a critical competitive asset as it provides an essential source of value to both user-innovators and open innovation platforms [103].

\subsection{The Mediating Role of Hedonic Emotion}

Consistent with the second hypothesis, this study discovered that hedonic emotion mediates the relationship between nonpecuniary motivation and user-generated innovation. An essential interpretation of this result is that an individual's dominant motive for developing innovation is the joy of the creative process rather than its value. This finding echoes studies by Stock et al. [13], who found that hedonic user motives drive solution novelty. The more an innovator is in the process for fun, the more novel the solution developed will be. Furthermore, this study's findings complement a study by Brinks [100], who noted that various emotions, including hedonic, shape the user innovation processes. Thus, it concurs with goal-setting theory which states that hedonically motivated user innovators engage in original and stimulating activities which derive spontaneous satisfaction [13].

\subsection{The Moderating Role of Testosterone}

The result supports the third and fourth hypotheses, which predicted that endocrinal testosterone moderates the relationship between nonpecuniary motivation and hedonic emotions and between hedonic emotions and user-generated innovation. It supported the argument put forward by Nicolaou et al. [14] that biological influences, which are largely unaccounted for in most traditional models, can shed light on unexplained behaviors. Testosterone moderated the path from nonpecuniary inspiration to hedonic feelings and subsequently from hedonic emotions to user-generated innovation. The study bridges the gap between behavioral endocrinology and innovation research, revealing testosterone's positive effects on human motivations and emotions. It helped to uncover the unexplored 
biological dispositions related to nonpecuniary motivations. Testosterone's influence manifests through a desire for gaining social status, territorial and competitive behavior, a sense of control and achievement, social extraversion, extending relationships, and in some cases, gender assertion [75,104,105]. The findings align with previous studies' results, which found that high testosterone levels are linked with increased neural reactivity to emotional stimuli. The results also supported the final hypothesis, suggesting that individuals might experience heightened emotional vigilance with high testosterone levels.

\subsection{Theoretical and Practical Implications of the Study}

This research underpins knowledge exchange on social platforms as a fundamental enabler of innovation. This is done by investigating nonpecuniary motivations that drive innovation behavior among user innovators on social media platforms. It has both theoretical and managerial implications. This research has applied a biopsychosocial lens to examine motivational drives using a moderated-mediation model. This way, theoretically, this research contributes to understanding how user innovators are motivated to innovate.

Furthermore, this research has implications for managers of social media platforms in open innovation. Social media companies can develop strategies that can foster the innovation environment by increasing NPM appeal to promote higher quality and intensity of user-generated innovation. It can be done by sharing their vision and objectives, enhancing intrinsic and emotional appeals, and attracting a wider user innovator body. The study has implications for new user innovators too. New user innovators can understand that their more in-depth biopsychosocial behaviors drive practical innovation. Given that hedonic actions foster innovation, extrinsic drives alone may not be well suited to user innovation aspirations. Understanding their intrinsic motivational movements may result in leveraging opportunities to achieve their goals and derive satisfaction and happiness.

\section{Conclusions}

This study has contributed to the theoretical research of open-innovation research. This study ties self-determination and emotion theories to the entrepreneurial spirit of innovating at the academic level, thus opening up a new and vast domain of research on nonpecuniary benefits in the context of social media platforms. By examining motivational drivers influencing user-generated innovation, this research has brought the theoretical debate of the open-innovation agenda to the forefront. Detailed analysis of user innovators' motivation on social media platforms is needed because adopting certain open-innovation practices has far-reaching implications for social media platforms. The study has opened the discussion of open innovation as a mechanism of the managed flow of knowledge transcending organizational boundaries based on nonpecuniary motivations. User innovators' incentive to share knowledge and information enables organizations' open-innovation models to foster value creation.

The results showed that higher testosterone levels had a significant impact on hedonic emotions and subsequently motivations for UGI. Testosterone levels influence the strength of the relationship between NPM and UGI. The study concludes that nonpecuniary motives due to biological disposition to testosterone drive individual innovation motives, especially in an open-innovation environment. On social media platforms, innovators value rewards such as fun, enjoyment, a sense of achievement, and camaraderie. This study is unique because the prior literature scarcely focused on physiological predispositions in user innovators' nonpecuniary motivations. Finally, the study's contribution is its conceptualization and testing of a moderated-mediation model to explain the nonpecuniary hedonic motives of open innovators.

\section{Limitations and Future Research Agenda}

The study has several limitations. The relatively small sample size is a potential limitation. The narrow lens of social media platforms can aid future research that focuses on extending the application framework to a wider open-innovation model; expanding 
the sample size for research verification purposes would benefit this limitation. The study is also limited to social media organizations, and user-innovation motivations may be different for firms outside the social media platforms. Furthermore, the user innovators within the selected sample may have slightly different motivational priorities, which this study did not capture. Innovation may take various forms and vary in degree and intensity, while this study takes only a generalized view of innovation. The measurement of testosterone levels through the $2 \mathrm{~d}: 4 \mathrm{~d}$ ratio is a probable estimation and is a proxy measure and may not be as accurate. The measurement instrument applied to investigate hedonic emotions can further benefit from being studied with different antecedents and successive research consequences.

Author Contributions: Conceptualization: T.A., V.R.; methodology: K.Q., V.B., M.A.; software: S.A.A., T.A.; formal analysis: V.R., V.B., M.A., S.A.A.; investigation: T.A., S.A.A., V.B., V.R., M.A., K.Q.; writing-review and editing: V.R., T.A., K.Q., S.A.A. All authors have read and agreed to the published version of the manuscript.

Funding: The research did not receive any external funding.

Institutional Review Board Statement: Not applicable.

Informed Consent Statement: Not applicable.

Data Availability Statement: Not applicable.

Acknowledgments: The authors would like to thank all the participants of the study for filling out the questionnaire and providing 2D:4D measurements.

Conflicts of Interest: The authors declare no conflict of interest.

\section{References}

1. Dahlander, L.; Gann, D.; Bessant, J.; Venables, T. How Open is Innovation? Creat. Wealth Knowl. 2013, 39, 699-709. [CrossRef]

2. West, J.; Salter, A.; Vanhaverbeke, W.; Chesbrough, H. Open innovation: The next decade. Res. Policy 2014, 43, 805-811. [CrossRef]

3. Von Hippel, E. Open User Innovation. In Encyclopedia of Human-Computer Interaction; Soegaard, M., Dam, R., Eds.; The Design Foundation: Aarhus, Denmark, 2013.

4. Bogers, M.; Afuah, A.; Bastian, B. Users as Innovators: A Review, Critique, and Future Research Directions. J. Manag. 2010, 36, 857-875. [CrossRef]

5. Von Hippel, E.; de Jong, J.; Flowers, S. Comparing Business and Household Sector Innovation in Consumer Products: Findings from a representative survey in the UK. Manag. Sci. 2012, 58, 1669-1681. [CrossRef]

6. Claus-Peter, H.; Ernst, J.P.; Rothlauf, F. Factors Driving Social Network Sites Usage; Springer: New York, NY, USA, 2015.

7. Kemp, S. Digital 2019 Reports. Hootsuite, We Are Social. 2019. Available online: https://datareportal.com/reports/digital-2019 -global-digital-overview. (accessed on 17 July 2020).

8. Ardolino, M.; Saccani, N.; Adrodegari, F.; Perona, M. A Business Model Framework to Characterize Digital Multisided Platforms. J. Open Innov. Technol. Mark. Complex. 2020, 6, 10. [CrossRef]

9. Lu, X.; Goldsmith, R.E.; Pagani, M. Two-Sided Markets and Social Media. In Organizations and Social Networking: Utilizing Social Media to Engage Customers; IGI Global Publishing: Hershey, PA, USA, 2013; pp. 197-213.

10. Muzellec, L.; Ronteau, S.; Lambkin, M. Two-sided Internet platforms: A business model lifecycle perspective. Ind. Mark. Manag. 2015, 45, 139-150. [CrossRef]

11. West, J.; Gallagher, S. Challenges of open innovation: The paradox of firm investment in open-source software. RED Manag. 2006, 36, 319-331. [CrossRef]

12. Hargreaves, E.; Agosti, C.; Menasché, D.; Neglia, G.; Reiffers-Masson, A.; Altman, E. Fairness in online social network timelines: Measurements, models and mechanism design. Perform. Eval. 2019, 129, 15-39. [CrossRef]

13. Stock, R.M.; Oliveira, P.; Von Hippel, E. Impacts of Hedonic and Utilitarian User Motives on the Innovativeness of User-Developed Solutions. J. Prod. Innov. Manag. 2014, 32, 389-403. [CrossRef]

14. Nicolaou, N.; Phan, P.H.; Stephan, U. The Biological Perspective in Entrepreneurship Research. Entrep. Theory Pract. 2021, 45, 3-17. [CrossRef]

15. Jung, K.; Lee, S.H.; Workman, J.E. Exploring Neglected Aspects of Innovation Function: Public Motivation and Non-pecuniary Values. Sci. Technol. Soc. 2016, 21, 435-464. [CrossRef]

16. West, J.; Bogers, M. Open innovation: Current status and research opportunities. Innovation 2017, 19, 43-50. [CrossRef]

17. Loewenstein, G.F. Risk as Feelings. Psychol. Bull. 2001, 127, 267. [CrossRef]

18. Dolcos, F.; Iordan, A.D.; Dolcos, S. Neural correlates of emotion-cognition interactions: A review of evidence from brain imaging investigations. J. Cogn. Psychol. 2011, 23, 669-694. [CrossRef] 
19. Franke, N.; Schreier, M.; Kaiser, U. The "I Designed It Myself" Effect in Mass Customization. Manag. Sci. 2010, 56, 125-140. [CrossRef]

20. Barrett, L.F. Emotions are real. Emotion 2012, 12, 413-429. [CrossRef] [PubMed]

21. West, J. Localized Knowledge Flows and Asymmetric Motivations in Open Innovation. J. Innov. Econ. 2020, 2, 181-196. [CrossRef]

22. Fichter, K. Innovation communities: The role of networks of promotors in Open Innovation. RED Manag. 2009, 39, 357-371. [CrossRef]

23. Piller, F.T.; West, J. Firms, Users, and Innovation: An Interactive Model of Coupled Open Innovation. In New Frontiers in Open Innovation; Chesbrough, H., Vanhaverbeke, W., West, J., Eds.; Oxford University Press: Oxford, UK, $2014 ;$ pp. $29-49$.

24. Randhawa, K.; Wilden, R.; Hohberger, J. A Bibliometric Review of Open Innovation: Setting a Research Agenda. J. Prod. Innov. Manag. 2016, 33, 750-772. [CrossRef]

25. Berthon, P.R.; Pitt, L.F.; McCarthy, I.; Kates, S.M. When customers get clever: Managerial approaches to dealing with creative consumers. Bus. Horizons 2007, 50,39-47. [CrossRef]

26. Lakhani, K.R.; Wolf, R.G. Why Hackers Do What They Do: Understanding Motivation and Effort in Free/Open Source Software Projects. In Perspectives on Free and Open Source Software; Feller, J., Fitzgerlad, B., Hissam, S.A., Lakhani, K.M., Eds.; MIT Press: Cambridge, MA, USA, 2005; pp. 3-21.

27. Choi, D.Y.; Perez, A. Online piracy, innovation, and legitimate business models. Technovation 2007, 27, 168-178. [CrossRef]

28. Laursen, K.; Salter, A. Open for innovation: The role of openness in explaining innovation performance among U.K. manufacturing firms. Strat. Manag. J. 2005, 27, 131-150. [CrossRef]

29. Baldwin, C.; Von Hippel, E. Modeling a paradigm Shift: From Producer Innovation to User and Open, Collaborative Innovation. Org. Sci. 2011, 22, 1399-1417. [CrossRef]

30. Baldwin, C.; Heiner, C.; Von Hippel, E. How User Innovations Become Commercial Products: A theoretical Investigation and Case Study. Res. Policy 2006, 35, 1291-1313. [CrossRef]

31. Leitão, J.; Pereira, D.; De Brito, S. Inbound and Outbound Practices of Open Innovation and Eco-Innovation: Contrasting Bioeconomy and Non-Bioeconomy Firms. J. Open Innov. Technol. Mark. Complex. 2020, 6, 145. [CrossRef]

32. Bogers, M.; Chesbrough, H.; Moedas, C. Open Innovation: Research, Practices, and Policies. Calif. Manag. Rev. 2018, 60, 5-16. [CrossRef]

33. Chesbrough, H.; Di Minin, A. Open Social Innovation. In Open Innovation: New Frontiers and Applications; Chesbrough, H., Vanhaverbeke, W., West, J., Eds.; Oxford University Press: Oxford, UK, 2014.

34. Gagné, M.; Deci, E.L. Self-determination theory and work motivation. J. Organ. Behav. 2005, 26, 331-362. [CrossRef]

35. Krause, A.E.; North, A.C.; Davidson, J.W. Using Self-Determination Theory to Examine Musical Participation and Well-Being. Front. Psychol. 2019, 10, 405-412. [CrossRef]

36. Cannon, W.B. The James-Lange Theory of Emotions: A Critical Examination and an Alternative Theory. Am. J. Psychol. 1987, 100, 567. [CrossRef]

37. Lange, C. The Emotions; Williams \& Wilkins: Baltimore, MD, USA, 1885.

38. Olsson, A.; Kopsida, E.; Sorjonen, K.; Savic, I. Testosterone and estrogen impact social evaluations and vicarious emotions: A double-blind placebo-controlled study. Emotion 2016, 16, 515-523. [CrossRef]

39. Nitschke, J.P.; Bartz, J.A. Lower digit ratio and higher endogenous testosterone are associated with lower empathic accuracy. Horm. Behav. 2020, 119, 104648. [CrossRef] [PubMed]

40. Nadler, A.; Camerer, C.F.; Zava, D.T.; Ortiz, T.L.; Watson, N.V.; Carré, J.M.; Nave, G. Does testosterone impair men's cognitive empathy? Evidence from two large-scale randomized controlled trials. Proc. R. Soc. B Boil. Sci. 2019, 286, 20191062. [CrossRef] [PubMed]

41. Buskens, V.; Raub, W.; Van Miltenburg, N.; Montoya, E.R.; Van Honk, J. Testosterone Administration Moderates Effect of Social Environment on Trust in Women Depending on Second-to-Fourth Digit Ratio. Sci. Rep. 2016, 6, 27655. [CrossRef] [PubMed]

42. Von Hippel, E. Democratizing Innovation; The MIT Press: Cambridge, MA, USA, 2005.

43. Shah, S.K.; Tripsas, M. The Accidental Entrepreneur: The Emergent and Collective Process of User Entrepreneurship. Strateg. Entrep. J. 2007, 1, 123-140. [CrossRef]

44. Von Hippel, E.; Katz, R. Shifting Innovation to Users via Toolkits. Manag. Sci. 2002, 48, 821-833. [CrossRef]

45. Franke, N.; Von Hippel, E. Satisfying Heterogeneous User Needs via Innovation Toolkits: The Case of Apache Security Software. Res. Policy 2003, 32, 1199-1215. [CrossRef]

46. Verreynne, M.-L.; de Oliveira, R.T.; Steen, J.; Indulska, M.; Ford, J.A. What motivates 'free' revealing? Measuring outbound non-pecuniary openness, innovation types and expectations of future profit growth. Science 2020, 124, 271-301. [CrossRef]

47. Alexy, O. Free Revealing: How Firms Can Profit from Being Open; Springer: Berlin, Germany, 2009.

48. Chitturi, R.; Raghunathan, R.; Mahajan, V. Form versus Function: How the Intensities of Specific Emotions Evoked in Functional versus Hedonic Trade-Offs Mediate Product Preferences. J. Mark. Res. 2007, 44, 702-714. [CrossRef]

49. Botti, S.; McGill, A.L. The Locus of Choice: Personal Causality and Satisfaction with Hedonic and Utilitarian Decisions. J. Consum. Res. 2011, 37, 1065-1078. [CrossRef]

50. Vittersø, J. The Feeling of Excellent Functioning: Hedonic and Eudaimonic Emotions. In Handbook of Community Well-Being Research; Springer Science and Business Media LLC: Berlin, Germany, 2016; pp. 253-276. 
51. Disabato, D.J.; Goodman, F.R.; Kashdan, T.B.; Short, J.L.; Jarden, A. Different types of well-being? A cross-cultural examination of hedonic and eudaimonic well-being. Psychol. Assess. 2016, 28, 471-482. [CrossRef]

52. De Dreu, C.K.; Baas, M.; Nijstad, B.A. Hedonic tone and activation level in the mood-creativity link: Toward a dual pathway to creativty model. J. Personal. Soc. Psychol. 2008, 94, 739-756. [CrossRef]

53. Berthon, P.; Pitt, L.; Kietzmann, J.; McCarthy, I.P. CGIP: Managing Consumer-Generated Intellectual Property. Calif. Manag. Rev. 2015, 57, 43-62. [CrossRef]

54. Chagas, G.M.D.O.; Aguiar, E.C. O papel de motivações utilitárias e hedônicas na cocriação de valor e sua relação com a experiência no AIRBNB. Rev. Bras. Pesqui. Tur. 2020, 14, 158-176. [CrossRef]

55. Patrick, M.; Michail, G.; Adamantia, P. Exploring the Business Potential of Social Media: A Utilitarian and Hedonic Motivation Approach. In Proceedings of the BLED Conference, Bled, Slovenia, 17-20 June 2012.

56. Kuusisto, J.; de Jong, J.P.; Gault, F.; Raasch, C.; von Hippel, E. Consumer Innovation in Finland: Incidence, Diffusion and Policy Implications; University of Vassa: Vaasa, Finland, 2013.

57. Hienerth, C.; Von Hippel, E.A.; Jensen, M.B. Innovation as Consumption: Analysis of Consumers' Innovation Efficiency. SSRN Electron. J. 2011, 43, 190-201. [CrossRef]

58. Füller, J.; Faullant, R.; Matzler, K. Triggers for virtual customer integration in the development of medical equipment-From a manufacturer and a user's perspective. Ind. Mark. Manag. 2010, 39, 1376-1383. [CrossRef]

59. Nambisan, S.; Baron, R.A. Different Roles, Different Strokes: Organizing Virtual Customer Environments to Promote Two Types of Customer Contributions. Organ. Sci. 2010, 21, 554-572. [CrossRef]

60. White, R.E.; Thornhill, S.; Hampson, E. Entrepreneurs and evolutionary biology: The relationship between testosterone and new venture creation. Organ. Behav. Hum. Decis. Process. 2006, 100, 21-34. [CrossRef]

61. Nicolaou, N.; Patel, C.; Wolfe, T. Testosterone and Tendency to Engage in Self-Employment. Manag. Sci. 2018, 64, 1825-1841. [CrossRef]

62. Bönte, W.; Procher, V.D.; Urbig, D. Biology and Selection into Entrepreneurship: The Relevance of Prenatal Testosterone Exposure. Entrep. Theory Pract. 2016, 40, 1121-1148. [CrossRef]

63. Unger, J.M.; Rauch, A.; Weis, E.; Frese, M. Biology (prenatal testosterone) psychology and entrepreneurial impact. J. Bus. Ventur. Insights 2015, 4, 1-5. [CrossRef]

64. Greene, F.J.; Han, L.; Martin, S.; Zhang, S.; Wittert, G. Testosterone is associated with self-employment among Australian men. Econ. Hum. Biol. 2014, 13, 76-84. [CrossRef] [PubMed]

65. Bettiga, D.; Bianchi, A.M.; Lamberti, L.; Noci, G. Consumers Emotional Responses to Functional and Hedonic Products: A Neuroscience Research. Front. Psychol. 2020, 11, 559779. [CrossRef] [PubMed]

66. Yue, C.; Zou, L.; Mei, J.; Moore, D.; Herold, F.; Müller, P.; Yu, Q.; Liu, Y.; Lin, J.; Tao, Y.; et al. Tai Chi Training Evokes Significant Changes in Brain White Matter Network in Older Women. Healthcare 2020, 8, 57. [CrossRef] [PubMed]

67. Chester, D.S.; DeWall, C.N. Combating the sting of rejection with the pleasure of revenge: A new look at how emotion shapes aggression. J. Pers. Soc. Psychol. 2017, 112, 413-430. [CrossRef] [PubMed]

68. Geurts, D.E.; Von Borries, K.; Volman, I.; Bulten, B.H.; Cools, R.; Verkes, R.-J. Neural connectivity during reward expectation dissociates psychopathic criminals from non-criminal individuals with high impulsive/antisocial psychopathic traits. Soc. Cogn. Affect. Neurosci. 2016, 11, 1326-1334. [CrossRef] [PubMed]

69. Buchholz, V.N.; Christiane, M.; Johannes, K.; Bernd, L.; Gerhard, G.; Mohler-Kuo, M.; Simon, F.; Simon, M.; Joseph, S. Lower Digit Ratio (2D:4D) Indicative of Excess Prenatal Androgen Is Associated With Increased Sociability and Greater Social Capital. Front. Behav. Neurosci. 2019, 13, 246-257. [CrossRef] [PubMed]

70. David, P.A.; Shapiro, J.S. Community-based Production of Open-Source Software: What do we Know about the Developers Who Participate? Inf. Econ. Policy 2008, 20, 364-398. [CrossRef]

71. Eisenegger, C.; Haushofer, J.; Fehr, E. The role of testosterone in social interaction. Trends Cogn. Sci. 2011, 15, 263-271. [CrossRef]

72. Newman, M.L.; Sellers, J.G.; Josephs, R.A. Testosterone, Cognition, and Social Status. Horm. Behav. 2004, 47, 205-211. [CrossRef]

73. Grant, V.J.; France, J.T. Dominance and testosterone in women. Biol. Psychol. 2001, 58, 41-47. [CrossRef]

74. Dabbs, J.M.; Bernieri, F.J.; Strong, R.K.; Campo, R.; Milun, R. Going on Stage: Testosterone in Greetings and Meetings. J. Res. Pers. 2001, 35, 27-40. [CrossRef]

75. Booth, A.; Granger, U.A.; Mazur, A.; Kivlighan, K.T. Testosterone and Social Behavior. Soc. Forces 2006, 85, 167-191. [CrossRef]

76. Hassler, M. Creative musical behavior and sex hormones: Musical talent and spatial ability in the two sexes. Psychoneuroendocrinology 1992, 17, 55-70. [CrossRef]

77. Herbert, J. Testosterone, Cortisol and Financial Risk-Taking. Front. Behav. Neurosci. 2018, 12, 101-124. [CrossRef]

78. Aldrich, H.E.; Martinez, M.A. Many are Called, but Few are Chosen: An Evolutionary Perspective for the Study of Entrepreneurship. Entrep. Theory Pract. 2001, 25, 41-56. [CrossRef]

79. Steward, H.W.; Watson, H.E.; Carland, J.C.; Carland, J.W. A proclivity for entrepreneurship, A comparison of entrepreneurs, small business owners, and corporate managers. J. Bus. Ventur. 1999, 14, 189-214.

80. Raasch, C.; Von Hippel, E.A. Amplifying User and Producer Innovation: The Power of Participation Motives. SSRN Electron. J. 2012. [CrossRef]

81. Muller, D.; Judd, C.M.; Yzerbyt, V.Y. When Moderation is Mediated, and Mediation is Moderated. J. Personal. Soc. Psychol. 2005, 89, 852-863. [CrossRef] 
82. Preacher, K.J.; Rucker, D.D.; Hayes, A.F. Addressing Moderated Mediation Hypotheses: Theory, Methods, and Prescriptions. Multivar. Behav. Res. 2007, 42, 185-227. [CrossRef]

83. Hayes, A.F. Introduction to Mediation, Moderation, and Conditional Process Analysis: A Regression-Based Approach; The Guilford Press: New York, NY, USA, 2013.

84. Eric, R.S.; Voss, K.E.; Crowley, A.E. Measuring the Hedonic and Utilitarian Dimensions of Attitude: A Generally Applicable Scale. In NA-Advances in Consumer Research; Brucks, M., Deborah, J., Eds.; MacInnis: Provo, UT, USA, 1997.

85. Gleason, E.D.; Fuxjager, M.J.; Oyegbile, T.O.; Marler, C.A. Testosterone release and social context: When it occurs and why. Front. Neuroendocr. 2009, 30, 460-469. [CrossRef]

86. Ma, J.; Lu, Y.; Gupta, S. User innovation evaluation: Empirical evidence from an online game community. Decis. Support Syst. 2019, 117, 113-123. [CrossRef]

87. Xu, Y.; Zheng, Y. The digit ratio (2D:4D) in China: A meta-analysis. Am. J. Hum. Biol. 2015, 27, 304-309. [CrossRef] [PubMed]

88. Redman, S.M.; Ash, A.C. Associations between the 2D:4D Proxy Biomarker for Prenatal Hormone Exposures and Symptoms of Developmental Language Disorder. J. Speech Lang. Hear. 2017, 60, 3226-3236.

89. Berenbaum, S.A.; Bryk, K.K.; Nowak, N.; Quigley, C.A.; Moffat, S. Fingers as a Marker of Prenatal Androgen Exposure. Endocrinology 2009, 150, 5119-5124. [CrossRef] [PubMed]

90. Hönekopp, J.; Watson, S. Meta-analysis of digit ratio 2D:4D shows greater sex difference in the right hand. Am. J. Hum. Biol. 2010, 22, 619-630. [CrossRef] [PubMed]

91. Siegmann, E.M.; Müller, T.; Dziadeck, I.; Mühle, C.; Lenz, B.; Kornhuber, J. Digit ratio (2D:4D) and transgender identity: New original data and a meta-analysis. Sci. Rep. 2020, 10, 1-11. [CrossRef]

92. Manning, J.T. Digit Ratio: A Pointer to Fertility, Behaviour, and Health; Rutgers University Press: New Brunswick, NJ, USA, 2002.

93. Preacher, K.J.; Hayes, A.F. Asymptotic and resampling strategies for assessing and comparing indirect effects in multiple mediator models. Behav. Res. Methods 2008, 40, 879-891. [CrossRef]

94. Edwards, J.R.; Lambert, L.S. Methods for integrating moderation and mediation: A general analytical framework using moderated path analysis. Psychol. Methods 2007, 12, 1-22. [CrossRef]

95. Wang, W.L.; Zhou, Y.Q.; Chai, N.N.; Li, G.H.; Liu, D.W. Mediation and moderation analyses: Exploring the complex pathways between hope and quality of life among patients with schizophrenia. BMC Psychiatry 2020, 20, 1-9. [CrossRef]

96. Suhr, D. Exploratory or Confirmatory Factor Analysis? In Proceedings of the 31st Annual SAS Users Group International Conference, San Francisco, CA, USA, 26-29 March 2006; pp. 200-231.

97. Larsen, R.; Russel, T.W. Estimating Confidence Intervals for Eigenvalues in Exploratory Factor Analysis. Behav. Res. Methods 2010, 42, 871-876. [CrossRef]

98. Tabachnik, B.G.; Fidell, L.S. Using Multivariate Statistics; Pearson International Education: London, UK, 2007.

99. Klaß, N. Open innovation in Media Innovation Research: A Systematic Literature Review. J. Media Bus. Stud. 2020, 17, 190-218. [CrossRef]

100. Brink, E.; Wamsler, C. Citizen engagement in climate adaptation surveyed: The role of values, worldviews, gender and place. J. Clean. Prod. 2019, 209, 1342-1353. [CrossRef]

101. Arshi, T. Is innovation a second-order construct: Clarifying the Formative and Reflective Measures of Innovation. Arch. Bus. Res. 2017, 5, 1-13. [CrossRef]

102. Macdonald, S. Nothing either good or bad: Industrial espionage and technology transfer. Int. J. Technol. Manag. 1993, 8, 95-105.

103. Ritala, P.; Olander, H.; Michailova, S.; Husted, K. Knowledge sharing, knowledge leaking and relative innovation performance: An empirical study. Technovation 2015, 35, 22-31. [CrossRef]

104. Neave, N. Hormones and Behaviour: A Psychological Approach; Cambridge University Press: Cambridge, UK, 2008.

105. Neave, N.; Wolfson, S. Testosterone, Territoriality and the 'Home Advantage'. Physiol. Behav. 2003, 78, 269-275. [CrossRef] 